\title{
Factors influencing the condition of vulnerability among the elderly
}

\section{Abstract}

Objective: Describe health conditions and life habits using Vulnerable Elders Survey-13 scores, with the aim of understanding the factors associated with the vulnerability of the elderly. Method: A quantitative, cross-sectional study was conducted in the Distrito Federal, Brazil. Data were collected by a questionnaire containing the Vulnerable Elders Survey-13 and other variables. Descriptive statistics, correlation and regression analyses were carried out. Results: 956 people aged 60 years and older living in the Distrito Federal were interviewed. Of these, $32.4 \%$ had scores equal to or greater than three, and were therefore classified as vulnerable. Some variables exhibited a positive relation with VES-13 score, with intensity ranging from very weak, in the case of systemic arterial hypertension $(p=0.035)$ and diabetes mellitus $(p=0.027)$, to moderate, as was the case with depression $(p<0.001)$, urinary loss $(p<0.001)$ and falls $(p<0.001)$. It was also observed that a $1 \%$ increase in the income of the elderly resulted in a reduction of 0.27 points $(p<0,001)$ in Vulnerable Elders Survey score, reducing vulnerability. Conclusion: Depression most influenced vulnerability score, followed by urinary and hearing loss. Public policies aimed at the promotion of the physical and mental health of the elderly and the creation of a propitious environment to increase income, through reinsertion into the labor market or welfare policies, can help to reduce vulnerability.

\footnotetext{
Secretaria de Estado de Saúde do Distrito Federal, Unidade Básica de Saúde do Itapoã, Diretoria de Atenção Primária a Saúde Região Leste. Itapoã, Brasília, Brasil.

2 Universidade Católica de Brasília, Programa de Pós-graduação em Gerontologia. Taguatinga, Brasília, Brasil.

3 Universidade Católica de Brasília, Programa de Pós-graduação em Economia. Taguatinga, Brasília, Brasil.
}

Funding: Fundação de Ensino e Pesquisa em Ciências da Saúde. Processo: 064.000.474/2013.
Thaís Garcia Amancio' $\mathbb{( D}$ Maria Liz Cunha de Oliveira² ${ }^{\mathbb{D}}$ Vitor dos Santos Amancio ${ }^{3}$ (D)

Keywords: Health of the Elderly. Risk Factors. Health Vulnerability. 


\section{INTRODUCTION}

Although the terms "frailty" and "vulnerability" are widely used in gerontological literature, they are not the same. In the present study, the term vulnerability shall be taken as referring to an increased risk of functional decline or death ${ }^{1}$ over a period of two years, in relation to biological and physiological factors.

Measures to appraise vulnerability are important for identifying elderly people at an increased risk of deterioration of health, who are an important target for interdisciplinary intervention. Identifying people aged 60 or over who are in a situation of vulnerability, with risk of functional decline and incapacity a large and significant step towards the construction and prioritization of adequate care for these patients ${ }^{2,3}$.

Studies exist in literature that describe screening instruments for functional decline and the quality of life of elderly people $e^{4,5}$. One of these is the Vulnerable Elders Survey-13 (VES-13) ${ }^{1}$, an instrument which predicts the occurrence of the functional disability, death, and institutionalization of the elderly person $^{6}$. The appraisal of vulnerability is extremely important, and this test has even been included in the Health Guidebook for the Elderly Person 2014 of the Brazilian Ministry of Health, where it was entitled the Protocol for Identification of the Vulnerable Elderly Person - VES-13. It is a key feature of this Health Guidebook?

The identification of health and living conditions related to the loss of functionality in the elderly person, represents an important contribution to the planning of public policies and interventions, which help people aged 60 or over live with more independence and less functional loss ${ }^{3}$. The health professional responsible for caring for the elderly person, when making an early identification of the factors that lead to functional disability, can also instigate interventions that would otherwise likely not have been considered.

The aim of the present study is to establish a link between the VES-13 score and health conditions and living habits, seeking to understand what factors are linked to the vulnerability of the elderly person.

\section{METHOD}

Through a quantitative and transversal study, we evaluated primary data related to the health and living conditions of elderly people resident in the Distrito Federal, Brazil. This study arose out of a survey carried out in the Distrito Federal between 2012 and 2015, entitled "The Health Situation, Life and Death of the elderly population living in the Distrito Federal"s.

The survey was carried out at the 15 regional health offices of the Distrito Federal, during the campaign for vaccination against influenza, carried out in 2014 , with the vaccination of $90.7 \%$ of the elderly population of the region.

The sample was stratified and is representative for each regional health office. Sample size calculation identified a need to interview 935 elderly persons in the DF.

The sample calculations were performed in two stages, the first stage calculated the sample of vaccination points and the second stage calculated the sample of the elderly population.

Stage 1: A stratified sample was taken of all the vaccination points, in proportion to the number of elderly people by region. The calculation base used was the set of fixed vaccination points in 2012 (146 in all). In order to obtain representative results for each health region, the study was carried out at one vaccination post for each Regional Health Office (RHO), with two vaccination points surveyed in the Ceilândia RHO, three in the Taguatinga RHO, and four in the Southern and Northern RHOs, resulting in a total of 20 vaccination points.

The vaccination points surveyed for each RHO were chosen at random.

Stage 2: To calculate a representative sample of elderly people who were to take part in the survey, the following formula was used:

$$
n=\frac{n_{0}}{1+\frac{n_{0}}{N}} \quad n_{0}=\frac{p(1-p)}{D^{2}},
$$


where "p" and " $\mathrm{D}$ " are coefficients of proportion and error related to the target public, and $\mathrm{N}$ is the total size of the subpopulation. Each RHO was considered as a subpopulation of the elderly population of the Distrito Federal.

For the sample calculation, population data based on the 2010 census of the Brazilian Institute for Geography and Statistics (or IBGE) was used'.

To select the elderly people who took part in the interviews, we used the systematic sampling technique, as follows the second of every two elderly people who provided their vaccination card at the vaccination point was invited to participate in the study. This person was given a Free and Informed Consent Form, approved by the research and ethics committee, which was read to with the interviewee, who was able to ask questions. If the individual agreed to take part in the study, the form was then duly signed.

The criteria for inclusion in the sample were: people aged 60 or over who lived in the Distrito Federal, In cases where the elderly person was unable to participate in the interview, then their companion should know the elderly person well enough to answer the questions of the questionnaire. Elderly people who were bedridden or those who did not arrive at the vaccination points were excluded from the study.

A total of 30 interviewers were selected, all of whom were people who worked with the elderly or had some proximity to the issue of ageing. These interviewers received 12 hours of training, divided into three sessions. The first session was become familiar with the questionnaire, standardize the questions and apply the questionnaire within the group; the second meeting was to apply the questionnaire among elderly people in the community; and the third was to resolve any concerns and make adjustments to the questionnaire, before drafting the final version.

The instrument for data collection was a questionnaire of closed questions, containing VES13 and also other questions about health and living conditions. The first version of the questionnaire was constructed by taking other questionnaires into account. This version was sent to four experts in ageing, and any readaptations were made.
On data collection days, the elderly people were approached while in the vaccination queue, and then invited to answer the questions of the interviewer in a more reserved space, close to the vaccination point.

The questionnaire as applied contained the following:

Vulnerable Elders Survey-13 (VES-13): This is a simple tool, available in the public domain, which identifies vulnerable elderly people living in the community. The authors of this instrument define a vulnerable elderly person as someone aged 65 or over, who has an increased risk of functional decline or death over the next two years ${ }^{1}$. This tool was developed and validated in the USA ${ }^{1}$ and a version culturally adapted for Brazil was released in 2012, in which an elderly person is considered as being 60 years old or over, in compliance with the terms of Brazilian legislation ${ }^{2}$. The Brazilian Ministry for Health used this instrument within the Health Guidebook for the Elderly Person, 2014, where it was given the name of Protocol for Identification of the Vulnerable Elderly Person VES $-13^{7}$.

The VES-13 gives points for aspects such as age, self-perception of health, physical limitations, and functional disabilities, generating a point score varying from 0 to 10 , with 0 representing the lowest degree of vulnerability and 10 the highest. The identification of an elderly person as vulnerable (with a point score of 3 or more) shows that vulnerable elderly people thus identified are 4.2 times more likely to experience functional decline or death over a period of two years ${ }^{1}$. In contrast, a score of less than three represents the absence of conditions of vulnerability. An analysis of 420 elderly people revealed that the risk of death or functional decline increases by $23 \%$ with a VES-13 score of three, and $60 \%$ with a VES-13 score of $\operatorname{ten}^{10}$. Awareness of the VES-13 score of the population therefore provides knowledge of the level of vulnerability. This instrument has a sensitivity of $82 \%$ and a specificity of $79 \%$, when used for elderly people without cancer ${ }^{11}$.

The other variables considered were: income, Body Mass Index (BMI), quantity of medication used daily, regular physical exercise, cigarette smoking, calf circumference, a fall in the last 12 months, urinary 
incontinence, hearing and sight problems which affect daily activities, and self-reports of medical diagnoses of high blood pressure, diabetes, arthritis, depression, and osteoporosis.

The study set out to discover whether there is any link between VES-13 test score and the variables as previously mentioned.

Excel 2013 was used for descriptive analysis. To identify the factors that could influence the vulnerability of elderly people, two separate approaches were used. The first seeks to identify the relationships of dependence that may exist between the selected variables and the VES-13 score. This analysis tries to identify whether any of the factors listed above is related to this score in some way. For the variables measured on a numeric scale, such as calf circumference, BMI and income, correlation analysis was used to identify if there was a relationship. For others, where the answers were given as contextual answers such as "has" or "doesn't have", the chi-squared test was used to see if a relationship existed. We also used Cramér's V test to check the intensity of the relationship, which could be considered very weak, weak, moderate, strong and very strong. The SPSS 22.0 software program was used to classify the same.

The second analysis was based on the estimation of a statistical model that seeks to capture, at specific points, the existing relationship between each variable and VES-13 score. For this, the following model was used:

VES13 $=\beta_{1}$ LnIncome $+\beta_{2} \operatorname{LnBMI}+\beta_{3} \operatorname{LnCalf}+$ $\beta_{4}$ Hypert. $+\beta_{5}$ Diab. $+\beta_{6}$ Depr. $+\beta_{7}$ Sight $+\beta_{8}$ Osteop. + $\beta_{9}$ Urine $+\beta_{10}$ Med. $+\beta_{11}$ Hearing $+\beta_{12}$ Fall $+\varepsilon$

Where:

LnIncome $=$ Natural logarithm of income as informed by the interviewee;

LnBMI= Natural logarithm of Body Mass Index, calculated based on the height and weight of the person interviewed;

LnCalf. $=$ Natural logarithm of the interviewee's calf circumference, as measured at the time of application of the questionnaire;

Hypert.= Hypertension;
Diab. $=$ Diabetes Mellitus;

Depr:= Depression;

Sight $=$ Vision problems that hinder daily activities;

Osteop. $=$ Osteoporosis

Urine $=$ Frequent urinary incontinence

Med. $=$ Number of types of medication that the interviewee takes daily.

Hearing.= Hearing problems that hinder daily activities.

Fall= Indicates whether the interviewee has had a fall over the last 12 months;

Finally, $\varepsilon$ is the estimation residue.

In a first analysis of the model, the presence of heteroscedasticity was noted. The robust model was therefore estimated, applying the correction as proposed by White, which corrects the possible bias of a previous model. In the case of income, BMI and calf circumference, which have different dimensions, the natural logarithm was applied to remove the bias in the result, and also to allow analysis in percentage terms, which means that the coefficient presented in Table 2 is the result of a $1 \%$ variation in these variables.

This research study was duly approved by the Research and Ethics Committee (REC) of the Foundation for Teaching and Research in the Life Sciences (or FEPECS), under Opinion Statement No. 143,846, on 12 November 2012, according to National Health Council Resolution No. 466 of 2012.

\section{RESULTS}

In this study, 956 people aged 60 or over, resident in the Distrito Federal (DF) were interviewed. Of this sample, $438(45.8 \%)$ were between 60 and 69 years old; $386(40.4 \%)$ were in their seventies, 1331 $(13.7 \%)$ were in their 80 and 99 years old and only one person was a hundred or older. In addition, 581 $(60.8 \%)$ of the elderly people were female and 373 $(39.0 \%)$ were male: two declined to answer.

Of those interviewed in this study, 456 (47.7\%) considered their health to be fair or poor. 
It was observed that $639(66.8 \%)$ of the elderly people had a VES-13 score between zero and two points, and $310(32.4 \%)$ had a score of three points or more. Table 1 describes the scores of the Protocol for the Identification of the Vulnerable Elderly Person, as recorded by the interviewees.

Table 1. Scores of the Protocol for the Identification of the Vulnerable Elderly Person (N=956), Brasília, DF, Brazil, 2014.

\begin{tabular}{ll}
\hline Scores & $\mathrm{n}(\%)$ \\
\hline 0 & $281(29.4)$ \\
\hline 1 & $242(25.3)$ \\
\hline 2 & $116(12.1)$ \\
\hline 3 & $117(12.2)$ \\
\hline 4 & $35(3.7)$ \\
\hline 5 & $28(2.9)$ \\
\hline 6 & $39(4.1)$ \\
\hline 7 & $58(6.1)$ \\
\hline 8 & $22(2.3)$ \\
\hline 10 & $5(0.5)$ \\
\hline Did not answer & $6(0.6)$ \\
\hline
\end{tabular}

Individuals who did not answer enough questions to obtain a VES-13 score were excluded. The presence or absence of a relationship between the variables was assessed by analysis of data cross-referencing and the application of the chi-squared test.

Positive relationships were found between the variables, albeit with differing intensities. In the case of hypertension $(p=0.035)$ and diabetes $(p=0.027$ ), the dependence between the variables was shown to be very weak, with Cramer's $V$ varying between 0 and 0.15 . In the cases of presence of arthritis $(p<0.01)$ and osteoporosis $(p<0.01)$ the relationship was weak, with a Cramer's V of between 0.15 and 0.20 . Variables with a moderate relationship, with Cramer's $\mathrm{V}$ ranging from 0.20 to 0.25 , were: depression $(p<0.01)$, sight problems $(p<0.01)$, urinary incontinence $(p<0.01)$, hearing problems $(p<0.01)$, regular physical exercise $(p<0.01)$ and occurrence of falls.

The relationship between smoking and VES-13 score was not statistically relevant, with $p=0.96$. In the case of numeric variables, correlation analysis identified an inverse yet weak relationship between income and VES-13 score $(p<0.01)$. Body mass index also revealed a weak and directly proportional correlation $(p=0.06)$, while there was a weak and inversely proportional relationship with calf circumference $(p=0.05)$. The number of medications applied revealed a weak positive correlation $(p<0.01)$.

Multivariate analysis identifies how much each variable contributes towards the vulnerability score, and depression was found to have the greatest influence, contributing 0.94 points, or almost one whole point, to VES-13 score $(p<0.01)$. Urinary loss adds an additional 0.73 points to the VES-13 score $(p<0.01)$. Each additional type of medication applied resulted in an increase of approximately 0.089 points to the VES-13 score $(p<0.01)$.

A summary of these results is shown in Table 2. The variables are shown in order of decreasing impact on VES-13 score. 
Table 2. Coefficients of multivariate analysis, Brasília, DF, Brazil, 2019.

\begin{tabular}{|c|c|c|c|}
\hline Variables & Coefficient & Standard Error & $p$-value \\
\hline Depression & 0.946 & 0.297 & 0.002 \\
\hline Body Mass Index ${ }^{*}$ & 0.830 & 0.742 & 0.263 \\
\hline Urinary incontinence & 0.730 & 0.211 & 0.001 \\
\hline Hearing problems & 0.670 & 0.231 & 0.004 \\
\hline Osteoporosis & 0.658 & 0.224 & 0.003 \\
\hline Sight problems & 0.616 & 0.209 & 0.003 \\
\hline Falls & 0.381 & 0.198 & 0.055 \\
\hline Income* & -0.278 & 0.073 & 0.000 \\
\hline Diabetes & 0.233 & 0.198 & 0.239 \\
\hline Number of Medications & 0.089 & 0.030 & 0.004 \\
\hline Hypertension & -0.055 & 0.200 & 0.783 \\
\hline Calf circumference $*$ & 0.050 & 0.683 & 0.942 \\
\hline
\end{tabular}

$\mathrm{R}^{2}=0.5563 ;$ F-test $<0.001 ; *$ Estimated variables shown as Natural logarithms;

As the p-value was over 0.1, the impact of calf circumference, hypertension, diabetes, and BMI could not be confirmed through multivariate analysis.

The estimated model obtained an $\mathrm{R}^{2}$ value of 0.55 , which suggests that the model used can explain over $55 \%$ of variations to VES-13, with the other $45 \%$ being explained by other variables not included in the model. As the model explains over $50 \%$, this can be considered satisfactory. Furthermore, the F-test score was less than 0.01 , which shows that the variables used, when taken jointly, are sufficient to explain the variations in the VES-13 scores.

An increase of 1\% in the income of the elderly person was found to cause a reduction of 0.27 points in VES-13 score $(p<0.01)$.

\section{DISCUSSION}

Of the elderly people interviewed, $32.4 \%$ were considered vulnerable, a proportion close to that found in the first study conducted on VES-13, in which $32.3 \%$ of the elderly people were found to have a score of three points or more.

Another study carried out with people aged 70 or over found that $38.0 \%$ of the sample had a point score $\geq 3$. Contrary to the findings of the first study, this study reached the conclusion that VES-13 shows a somewhat limited predictive precision when predicting mortality and admission to emergency units ${ }^{12}$.

Depression known to be a factor that reduces functional capacity, but in this study the presence of the same increased VES-13 score by almost a whole point. Among elderly patients with heart problems, depression has been found to be very common, with a major impact upon independence and also upon the quality of life of these people ${ }^{13}$. Another study carried out in Lafaiete Coutinho, in the Brazilian state of Bahia, showed that elderly people with prior symptoms of depression ran a greater risk of becoming dependent on others, even for the most basic activities of daily living, regardless of their gender, age bracket, per-head family income, presence of diabetes, use of medication, or level of physical activities ${ }^{3}$.

A study carried out on housebound patients showed that the presence of urinary incontinence also raised the mortality rate, which was $24.9 \%$ over a two and a half year period, compared to a rate of $12.8 \%$ mortality in the group without urinary incontinence ${ }^{14}$. Another study, this one in 2018, found data that confirmed that elderly people with urinary incontinence had a greater likelihood of functional disability for activities of daily living ${ }^{15}$. 
Income is a mechanism for social protection, and an increase in salary is linked to a reduction in VES-13 points, and hence to a reduction in the risk of disability or death. In 2003, 10.8\% of elderly people had no income, representing a total of 1.5 million individuals, of whom $80 \%$ were women, generally of more advanced age, economically disadvantaged, and with a reduced role in the employment market, as well as reporting worse conditions of health and lower functional autonomy ${ }^{16}$.

In 2014, the income of elderly people was made up of retirement pay (53.4\%), income from work (40.8\%), pensions and other sources, including the state pension. Since the 1990 s, there has been a fall in the proportional participation of elderly people in the workforce, with the work activities of elderly people declining by 12\%. This was because in 2013 the average age of retirement among Brazilians was 54 years old, affecting the decision to retire while still able to work. The fact that the elderly retiree experiences unstable employment conditions upon returning to work also has an influence on his or her return to the employment market ${ }^{17}$.

The main bias contained in this study is the fact that it does not include housebound elderly people, as these have the option of being vaccinated at home. This means that some of the more dependent elderly people would not attend the vaccination points, and hence would have no possibility of being interviewed. The prior training of the evaluators for the application of the interviews and of the physical performance tests largely rules out the possibility of evaluation

\section{REFERENCES}

1. Saliba D, Elliott M, Rubenstein LZ, David HS, Roy TY, Caren JK, et al. The Vulnerable Elders Survey: a tool for identifying vulnerable older people in the Community. J Am Geriatr Soc [Internet]. 2001 [acesso em 25 jan. 2018];49(12):1691-9. Disponível em: https://onlinelibrary.wiley.com/doi/full/10.1046/ j.1532-5415.2001.49281.x?sid=nlm\%3Apubmed

2. Maia FOM, Duarte YAO, Secoli SR, Santos, JLF, Lebrão ML. Adaptação transcultural do Vulnerable Elders Survey -13 (VES-13): contribuindo para a identificação de idosos vulneráveis. Rev bias. However, there is the possibility that the results of self-reported measurements may be influenced by cultural and social factors.

\section{CONCLUSION}

The results of this study show that a significant part of the elderly population demonstrate a risk of vulnerability, especially with the effects of variables such as depression, urinary incontinence, hearing difficulties, osteoporosis, visual difficulties, falls, number of medications in use, and family income, which interfere with the vulnerability score of the elderly person.

A rise in income, even if small $(1.0 \%)$, reduces the Vulnerable Elders Survey-13 score and, hence, the elderly person's degree of vulnerability.

The identification of the vulnerability of elderly people prior to significant functional decline facilitates the establishing a course of action that provides greater independence and quality of life for these individuals, as illnesses and health disorders can harm functional systems through a range of mechanisms, and can even lead to disability and/ or death.

Efficient government policies aimed at the promotion of physical and mental health for the wellbeing of the elderly population, and the creation of an environment that helps to boost income through reinsertion in the employment market or through welfare policies, can help to reduce vulnerability.
Esc Enferm USP [Internet]. 2012 [acesso em 17 set. 2015];46(Esp):116-22. Disponível em: http://www.scielo.br/scielo.php?script=sci_ arttext\&pid=S0080-62342012000700017

3. Matos FS, Jesus CS, Carneiro JAO, Coqueiro RS, Fernandes MH, Brito TA. Redução da capacidade funcional de idosos residentes em comunidade: estudo longitudinal. Ciênc Saúde Colet [Internet]. 2018 [acesso em 01 ab.r 2019]; 23(10):3393-3401. Disponível em: https://scielosp.org/scielo.php?script=sci_ arttext\&pid=S1413-81232018001003393 
4. Deckx L, Akker MVD, Daniels L, Jonge E, Bulens P, Tjan-Heijnen VCG. Geriatric screening tools are of limited value to predict decline in functional status and quality of life: results of a cohort study. Fam Pract. 2015 [acesso em 30 mar. 2019];16(30):1-12. Disponível em: https://www.ncbi.nlm.nih.gov/pmc/ articles/PMC4358725/

5. Smets IHGJ, Kempen GIJM, Janssen-Heijnen MLG, Deckx L, Buntinx FJVM, Akker MVD. Four screening instruments for frailty in older patients with and without cancer: a diagnostic study. BMC Geriatr [Internet]. 2014 [acesso em 20 mar. 2019];14:(26):1-8. Disponível em: https://www.ncbi.nlm.nih.gov/pmc/ articles/PMC3938903/

6. Bongue B, Buisson A, Dupre C, Beland F, Gonthier R, Crawford-Achour E. Predictive performance of four frailty screening tools in community-dwelling elderly. BMC Geriatr [Internet]. 2017 [acesso em 20 mar. 2019];17(262):1-9. Disponível em: https://www. ncbi.nlm.nih.gov/pmc/articles/PMC5681791/

7. Brasil. Ministério da Saúde. Caderneta de Saúde da Pessoa Idosa [Internet]. Brasília, DF: MS; 2014 [acesso em 05 dez. 2017]. Disponível em: http://bvsms.saude. gov.br/bvs/publicacoes/caderneta_saude_pessoa_ idosa_3ed.pdf

8. Oliveira MLC, Amancio TG. Situação de saúde, vida e morte da população idosa residente no Distrito Federal [Internet]. Curitiba: CRV; 2016 [acesso em 19 dez 2017]. Disponível em: http://www.saude.df.gov. br/images/Programas/2016/livro.pdf

9. [Brasília]. Governo do Distrito Federal, Secretaria de Saúde do Distrito Federal, Subsecretaria de Vigilância à Saúde, Diretoria de Vigilância Epidemiológica, Gerência de Informação e Análise de Situação em Saúde. Pessoas residentes do DF, de acordo com a faixa etária e distrito de residência adotado no SIM, Sinasc e Sinan: 2008 - 2012. [S. 1.]: [S. n.]; 2013.

10. Min LC, Elliott MN, Wenger NS, Saliba D. Higher vulnerable elders survey scores predict death and functional decline in vulnerable older people. J Am Geriatr Soc [Internet]. 2006 [acesso em 15 dez. 2017];54(3):507-11. Disponível em: https:// onlinelibrary.wiley.com/doi/full/10.1111/j.15325415.2005.00615.x
11. Smets IH, Kempen GI, Janssen-Heijnen ML, Deckx L, Buntinx FJ, van den Akker M. Four screening instruments for frailty in older patients with and without cancer: a diagnostic study. BMC Geriatr [Internet]. 2014 [acesso em 31 out. 2016];14:1-8. Disponível em: https://bmcgeriatr.biomedcentral. com/articles/10.1186/1471-2318-14-26

12. Wallace E, McDowell R, Bennett K, Fahey T, Smith SM. External validation of the Vulnerable Elder's Survey for predicting mortality and emergency admission in older community-dwelling people: a prospective cohort study. BMC Geriatr [Internet]. 2017 [acesso em 01 abr. 2019];17:1-8. Disponível em: https://bmcgeriatr.biomedcentral.com/ articles/10.1186/s12877-017-0460-1

13. Rodrigues GHP, Gebara OCE, Gerbi CCS, Pierri $\mathrm{H}$, Wajngarten M. Depressão como determinante clínico de dependência e baixa qualidade de vida em idosos cardiopatas. Arq Bras Cardiol [Internet]. 2015 [acesso em 25 jan. 2018];104(6):443-9. Disponível em: http://www.scielo.br/scielo.php?script=sci_ arttext\&pid=S0066-782X2015000600003

14. John G, Gerstel E, Jung M, Dällenbach P, Faltin, $\mathrm{D}$, Petoud $\mathrm{V}$, et al. Urinary incontinence as a marker of higher mortality in patients receiving home care services. BJU Int [Internet]. 2014 [acesso em 25 jan. 2018];113(1):113-9. Disponível em: https:// onlinelibrary.wiley.com/doi/full/10.1111/bju.12359

15. Kessler M, Facchini LA, Soares MU, Nunes BP, França SM, Thumé E. Prevalência de incontinência urinária em idosos e relação com indicadores de saúde física e mental. Rev Bras Geriatr Gerontol [Internet]. 2018 [acesso em 01 abr. 2019];21(4):409-19. Disponível em http://www.scielo.br/scielo.php?script=sci_ arttext\&pid=S1809-98232018000400397\&lng=pt\&nr $\mathrm{m}=$ iso\&tlng $=\mathrm{pt}$

16. Camarano AA. Mecanismos de proteção social para a população idosa brasileira [Internet]. Rio de Janeiro: IPEA; 2006 [acesso em 25 jan. 2018]. Disponível em: http://www.ipea.gov.br/portal/images/stories/PDFs/ TDs/td_1179.pdf

17. Alcântara AO, Camarano AA, Giacomin KC. Política nacional do idoso: velhas e novas questões [Internet]. Rio de Janeiro: IPEA; 2016 [acesso em 01 abr. 2019]. p. 91-3. Disponível em: http://www.ipea.gov.br/ portal/images/stories/PDFs/livros/livros/161006_ livro_politica_nacional_idosos.PDF 